GONZALO LEIVA QUIJADA

INSTITUTO DE ESTÉTICA

FACULTAD DE FILOSOFÍA

PONTIFICIA UNIVERSIDAD

CATÓLICA DE CHILE

SANTIAGO, CHILE

GLEIVAQ@UC.CL
1. Este texto surge del proyecto FONDART 2015

"En el Umbral del Olvido" (Creador Samuel Shats,

Curador Gonzalo Leiva Q.) y del proyecto de inves-

tigación "Memorias y Holocaustos" desarrollado

en la Universidad de Sao Paulo, convenio con

UNICAMP y la PUC de Chile (Instituto de Estética,

Gonzalo Leiva Q.), 2016-2018.

\section{Testimonios / documentación: apostillas a la memoria visual}

\author{
Testimonials / Documentation: Apostilles to Visual Memory
}

Resumen. La investigación se sitúa en tres momentos de la memoria visual desde Chile. El primero, en la conformación del testimonio como dispositivo estético. El segundo, dentro del documento como construcción histórica. De esta manera, el tercer momento reflexiona sobre la configuración del post-testimonio. Todas instancias que dan cuenta de fases y diálogos entre la visualidad y la temporalidad.

Palabras clave: cartografía de la memoria, documento, memoria visual, testimonio, visualidad.

\begin{abstract}
The research is addressed on three moments of the visual memory of Chile. The first one, the testimony conformation as an aesthetic device. The second one, inside the document as a historical construction. Finally, the third moment has its thoughts on the post-testimony construction. All kind of instances that account for phases and dialogues between visuality and temporality.
\end{abstract}

Keywords: cartography of memory, document, testimony, visual memory, visuality.

\section{Introducción}

Las experiencias traumáticas de las grandes conflagraciones mundiales y en particular los períodos dictatoriales en América Latina (desde 1964 con el derrocamiento del presidente de Brasil Joao Goulart en adelante), instalaron las "políticas de la memoria" (Collins et al., 2013) como experiencia de reflexión y reconocimiento societal sobre el padecimiento producto de la violencia; en este contexto los testimonios visuales jugaron roles protagónicos.

De este modo, recorreremos un periplo sobre algunos testimonios y documentación que obedecen a un intento de construir una "cartografía de la memoria" (Leiva, 2016), instalados en el universo de representaciones testimoniales desde sus sentidos reales y simbólicos. La propuesta analítica que inquirimos propone un trazado por el testimonio documental desde la dimensión del contenido formal, es decir del paso de la fórmula monocroma al color, a su mensaje y recepción. ¿Dichos materiales creativos que fueron iluminando las zonas del horror en nuestra modernidad sufren variaciones significativas, pregnancias ulteriores, mayor grado de verosimilitud? ¿Qué ocurre con esta memoria visual en Chile? ${ }^{1}$ Son los testimonios estructuras creativas dialogantes que percibo como faros en el mar de la incertidumbre, una perspectiva que traza un horizonte común. Enuncian más o menos direccionalmente la presencia de un quiebre sórdido y cuando lo abyecto (Freud, 1976) se convierte en reincidente y familiar, no solo corrobora "lo ominoso" sino que se transforma en algo directamente brutal. Por lo mismo, la marca sentida de las imágenes que materializan el padecimiento, es la arremetida existencial e histórica desde la cotidianidad afectada. En efecto, para tantas víctimas que fueron violentadas por 
la tortura, el encierro, la violación de sus derechos básicos, estas imágenes constituyen su bandera de lucha. Lo abyecto es la presencia de lo mortuorio, pues lo abyecto solicita y pulveriza simultáneamente al sujeto (Kristeva, 1982). Desde esta perspectiva dialogo con el escritor Roberto Bolaños, pues establece que todos estos testimonios hablan de una barbarie compleja y terminal: "lo más brutal es la muerte. Ahora y hace años y dentro de unos años: lo brutal siempre es la muerte" (Bolaño y Braithwaite, 2006, p. 93). La propuesta argumental indica un recorrido por diferentes corpus analizando sus motivaciones y sus planteamientos estéticos. De un modo evidente, mi itinerancia está consignada desde una perspectiva hermenéutica donde el pensamiento de Paul Ricoeur está en el centro de la discusión (Ricoeur, 2000, p. 14).

\section{El testimoniar del siglo $\mathbf{x I X}$}

El conjunto de obras propuestas nos posibilita un trazado cultural específico. Una suerte de gran estela silenciosa entre dos universos de conocimiento que no necesariamente se unifican y relacionan: la memoria y la representación. Serán estos dos componentes los hilos secretos que fueron articulando tramas de significación cultural de este proyecto.

El foco de la perspectiva enunciativa, está concentrado en el testimonio, como un discurso narrativo que ejercido para el dominio público se realiza de manera oral, escritural, material o audiovisual. Los fundadores franceses de la Escuela de los Anales permitirán epistemológicamente el ingreso de este planteamiento al incorporar otras fuentes en la consideración y construcción testimonial, que originalmente se circunscribían al testimonio escrito. El testimonio es siempre fragmentario, se debe conformar múltiples testimonios para establecer la veracidad, confiablidad de la construcción histórica. Además, posteriormente tras la crítica de la fuente, deben ser interpretadas en contexto de una producción y recepción que va conformando una memoria histórica (Villanova, 2006, p. 102). Para esta investigación el testimonio lo adscribimos al concepto de "dispositivo estético" como instancia que posibilita aglutinar los dispersos rastros de una memoria difusa. Los dispositivos se entienden dentro del juego del poder y de la dominancia cultural (Foucault, 2008). Analizar un dispositivo consistiría entonces en descubrir esas prácticas que constantemente son singulares porque su emergencia siempre responde a un acontecimiento históricamente particular (García Fanlo, 2007). Al definir Agamben los dispositivos los establece como entidades con capacidad de capturar, orientar, determinar, interceptar, modelar, controlar y asegurar los gestos, las conductas, las opiniones y los discursos de los seres vivientes. Para el autor son respuestas en momentos históricos precisos (Agamben, 2011). Desde esta perspectiva global, señalamos los dispositivos como articuladores de redes de significación, donde se unifican rastros humanos, constructos materiales y producciones simbólicas. Asimismo, el testimonio se constituye en dispositivo encarnado cuyos límites se encuentran en las distorsiones y posibilidades de ampliar nuevas recepciones. Con mayor celeridad el dispositivo testimonial visual se restablece en un oxímoron de la modernidad, una suerte de profanación y salida de rango del estadio enunciativo de una verdad en el complejo escenario trazado por el capitalismo y su dominación. En el entendido de la unidad epistemológica que unifica a Foucault y Agamben, ambos ponen el acento de los dispositivos como procesos de subjetivación que fueron resultando 
del cuerpo a cuerpo entre estos y los individuos. De un modo sintomático, el dispositivo testimonial configura una emanación de la temporalidad histórica imbricada en la memoria personal y colectiva. Pues un testimonio en este contexto es una escenificación de lucha agonística entre las fuerzas de dominación de la corriente principal y los afanes de resistencia de la individualidad. Por esto mismo, los testimonios asumen desde la sensibilidad artística otra arista que es necesario hacer notar, pues el testimonio visual es el despliegue de la identidad no sumisa de la misión artística y de los poderes que buscan atarla para controlarla.

Al respecto y especificando el campo del dispositivo (Deotte, 2013), el filósofo nos recuerda que tanto el museo, el cine como la fotografía conforman entre otros nuevos dispositivos, aparatos estéticos e instrumentos culturales que buscan instaurar renovaciones espacio-temporales y por lo mismo enuncian visibilidades. Además, estos aparatos estéticos en su despliegue facultan maduración del universo simbólico, pues se instauran como poéticas refundadoras de las percepciones temporales. De este modo, recepción, aparato y significación testimonial establecen una tríada de acepción cultural que ahonda el peso de lo visual en lo contemporáneo y del dispositivo como estrategia del despliegue argumental del testimonio más allá del documento escritural. El dispositivo testimonial artístico que enunciamos es el que buscaba la verosimilitud desde el canon estético del estilo neoclásico, ajustando desde la naturaleza su estructura de representación. En el período premoderno, la pintura constituye la dominancia sin contrapeso en el campo cultural por medio de la institucionalidad de la Academia de Bellas Artes. Como la labor artística estaba mermada por un dispositivo estético canónico, que establecía reglas "claras y distintas" donde se asumía al modelo externo como lo único imitable. En esta concepción estética, el color jugaba un rol funcional y operativo. Pero al avanzar el siglo XIX, el dispositivo se fue morigerando dada la irrupción de las artes industriales que construyeron en la reproducción objetivada un ingreso a un mundo controlado por la mirada que estaba al servicio de la razón dominante. De este modo, se constituye el paradigma representacional de la memoria visual moderna. Entre sus componentes, destaca la fotografía al emerger, dominada por la representación positivista y en ese sentido coincidente con el paradigma de representación de los hechos objetivos. Así, la imagen fotográfica se estableció como un dispositivo al servicio de la civilidad y encarnación evidente de la idea del progreso. La fotografía se articula entonces como representación moderna supeditada al deseo de fundar identidades visuales que buscan preservar la memoria de las proezas construidas por los procesos industriales. La maniobra de la historia fotográfica se posiciona en cuanto testigo fiable de gravitación histórica. No deja de ser inquietante que el poder central -el Estado y las clases dominantes- se apoderaran de la fotografía para prácticas muy precisas: control de la población peligrosa, promoción de la coacción y de los aparatajes institucionales de represión con el método Bertillon aplicable a cárceles, correccionales, hospitales y manicomios.

Ahora bien, desde la emergencia del paradigma físico-químico fotográfico se fue estableciendo una representación por encuadres en blanco y negro. De tal modo, que la memoria de buena parte del siglo xIX y del siglo XX se recubre de la práctica del médium por el registro argéntico del blanco/negro. El color aparece añadido, con trazos específicos y dominados por los deseos de "iluminar" aspectos puntuales: las joyas, las mejillas y vestidos de las mujeres que posaban. 
La irrupción de la croma, es decir del color, no pareció importunar la esencia del relato de la memoria que estaba muy anclado en el duotono hasta bien entrado el siglo xx y que se constituye hasta el día de hoy en una prueba convincente. Al respecto, el libro y exhibición reciente denominada "Relatos de luchas e ideales", es un ejercicio testimonial realizado en el Parque Cultural de Valparaíso que busca "desde la borradura fallida, que dejó fisuras por donde se han ido expandiendo espacios que nos hablan del cómo y dónde ocurrieron los hechos, persistencia que nos ha permitido poder comprender este anhelo de justicia que hay implícito en el hacer memoria": una exposición de fotografías blanco y negro acompañaba el relato testimonial de personas presas en esas mismas instalaciones hoy puesta al servicio cultural. Una manifestación precisa del poder estético y simbólico del blanco y negro (Parque Cultural de Valparaíso, 2016, p. 23).

\section{Documentar el siglo $\mathbf{x x}$}

El documentar es una acción sobre la realidad de los testimonios con objetivos precisos, es un dispositivo cultural de la modernidad, en particular de la disciplina histórica. Al documentar se realiza la operación de establecer condiciones y posibilidad de comprensión de un sistema cultural desde el "utillaje mental" de una época. La investigación histórica construye el "acontecimiento" y para esto requiere variada documentación; mucha de ella se encuentra en los archivos. El documentar implica un ejercicio de plasticidad del tiempo, que posibilita y permite renacer con las narrativas y estallidos textuales (Febvre, 1947/1970, p. 232) de los hechos prominentes desde la guerra de trincheras, la "Gran Guerra" hasta los sucesos de la calle con la dinámica establecida por las nuevas demandas sociales.

Ahora bien, sin duda que el trabajo documental de los conflictos, en particular las dimensiones fratricidas visualizadas en las grandes encrucijadas mundiales, nos dirigen hacia la Segunda Guerra Mundial direccionadas desde el trauma de la Shoah o el Holocausto. Las miles de imágenes y documentales, en particular la fuerza del testimonio elaborada por Alain Resnais en su filme Nuit et Brouillard (1956) da cuenta de estos relámpagos axiales en la conciencia de los crímenes de "lesa humanidad"; justo en momentos que los últimos campos de refugiados se estaban cerrando en Europa. La barbarie había dejado un registro oficial que fue transformado por la audacia fílmica de Resnais en un documento que critica la operatividad nazi-capitalista de exterminio contra miles de personas y enrostra el silencio de Occidente frente a tal designio (Hilberg, 2005). Nuevamente una buena parte de la documentación es recogida de documentales institucionales del régimen nazi y de las tropas aliadas al momento de la liberación. El registro fue realizado en blanco y negro; de hecho se pensaba por mucho tiempo que la documentación en esta clave visual era más fidedigna al registro de la memoria histórica. Desde aquí, el color vivió un momento reflexivo, no era necesario ser descriptivo ni explícito para mostrar la "cultura del horror". Hay intentos con las nuevas tecnologías de nutrir el paradigma mimético y en este sentido el croma se ve como un recurso ineludible, incluso hay algunos registros históricos que han sido coloreados digitalmente. Se produce una extrañeza por la pervivencia de estas prácticas. Incluso se ha llegado a afirmar que el blanco y negro es parte de la fuerza de la verdad testimonial; en este sentido hay que ver algunos ejemplos para dilucidar esta cuestión central en la representación de la memoria. El triunfo de la tecnología digital coloca a las personas frente a la necesidad de una "alfabetización visual", 
con mayor urgencia dada la emergencia de una cultura global -la cultura mundo- (Lipovetsky y Serroy, 2010) que busca eclipsar las fronteras y hacer equivalentes "denominadores culturales", por lo general de la cultura de masas que en la "entre-tensión" borra las huellas de lo grave para dejar la liviandad y el vaciamiento. Al respecto ejemplos evidentes se ven tipificados por los juegos de video, los tele realities, entre otros.

Por lo mismo, el documento visual necesita establecer un lenguaje comprensible. Por cierto, los conceptos metafórico-analíticos legados por Barthes, Benjamin y Sontag posibilitan establecer metodologías de interpretación. Lo mismo es para las propuestas de carácter hermenéutico objetivo como los formulados por la perspectiva iconográfica-iconológica. Todos estos enfoques tienen en común que primero se realiza una descripción y análisis de los elementos formales, seguida por una interpretación reflexiva que también interroga sobre el origen de la imagen. El mayor desafío consiste en establecer una intertextualidad (Bajtin, 1989) entre texto e imagen, ya que un texto se puede dividir y analizar por párrafos, mientras que una foto principalmente se caracteriza por la simultaneidad perceptiva.

Las imágenes incitan la curiosidad y engendran la nominalización, la comparación y de paso facultan posibles interpretaciones. Para algunos autores la fotografía es "otra forma de contar" (Berger y Mohr, 2013). Con un lenguaje simple y directo, todos se sienten inclinados a establecer relatos a partir de las fotografías, de este modo posibilita transformar la situación "congelada" de una imagen en continuum que dialoga con los otros dispositivos visuales. Por eso no debe llamar la atención que la exposición artística más exitosa que ha logrado Chile se produjo en los años sesenta. El proyecto nacional "Rostro de Chile”, fue un dispositivo visual con muchas fotografías tamaño póster. Dicha exposición fue la primera que sintetizó y promocionó el nuevo país que se buscaba crear. En otras palabras, permitió mostrar mediante la fuerza del testimonio fotográfico una realidad nacional como proyecto de promesa. "Rostro de Chile" se constituyó en un referente de la visualidad chilena, pero al mismo tiempo una importante reflexión desde lo original, donde se conformaba y soñaba la identidad del país cara con los ritmos de transformación temporales y espaciales, además de los compromisos socioculturales que la ciudadanía esperaba que se asentaran.

Históricamente el proyecto se generó el año 1959 y su trabajo expositivo circuló desde 1960 hasta 1969. Para la exhibición se seleccionaron finalmente 410 imágenes, de un total de siete mil negativos, las que fueron expuestas en su inauguración en los patios de la Casa Central de la Universidad de Chile. El organizador fue Antonio Quintana y el departamento fotográfico de la Universidad de Chile, donde participaban los más destacados autores de la producción visual de la época, como el mismo Quintana, Roberto Montandón, Sergio Larraín, Baltazar Robles, Luis Ladrón de Guevara, Mario Guillard, Patricio Guzmán, Domingo Ulloa, además de Ignacio Hochhausler y Víctor Kabath. La propuesta curatorial estuvo restringida a dos géneros fotográficos: relación retrato-paisaje, siendo el referente de la exposición: The Family of Man, la más destacada exposición fotográfica presentada en el MoMA y que llegó a Chile a finales de los años cincuenta.

Ahora bien, "Rostro de Chile" tiene en la itinerancia su clave del éxito expositivo. En Chile estuvo en seis lugares destacados de provincia. También la exposición viajó al extranjero gracias a la ayuda del Ministerio de Relaciones Exteriores que permitió su difusión por América Latina. Más tarde, recorrió 


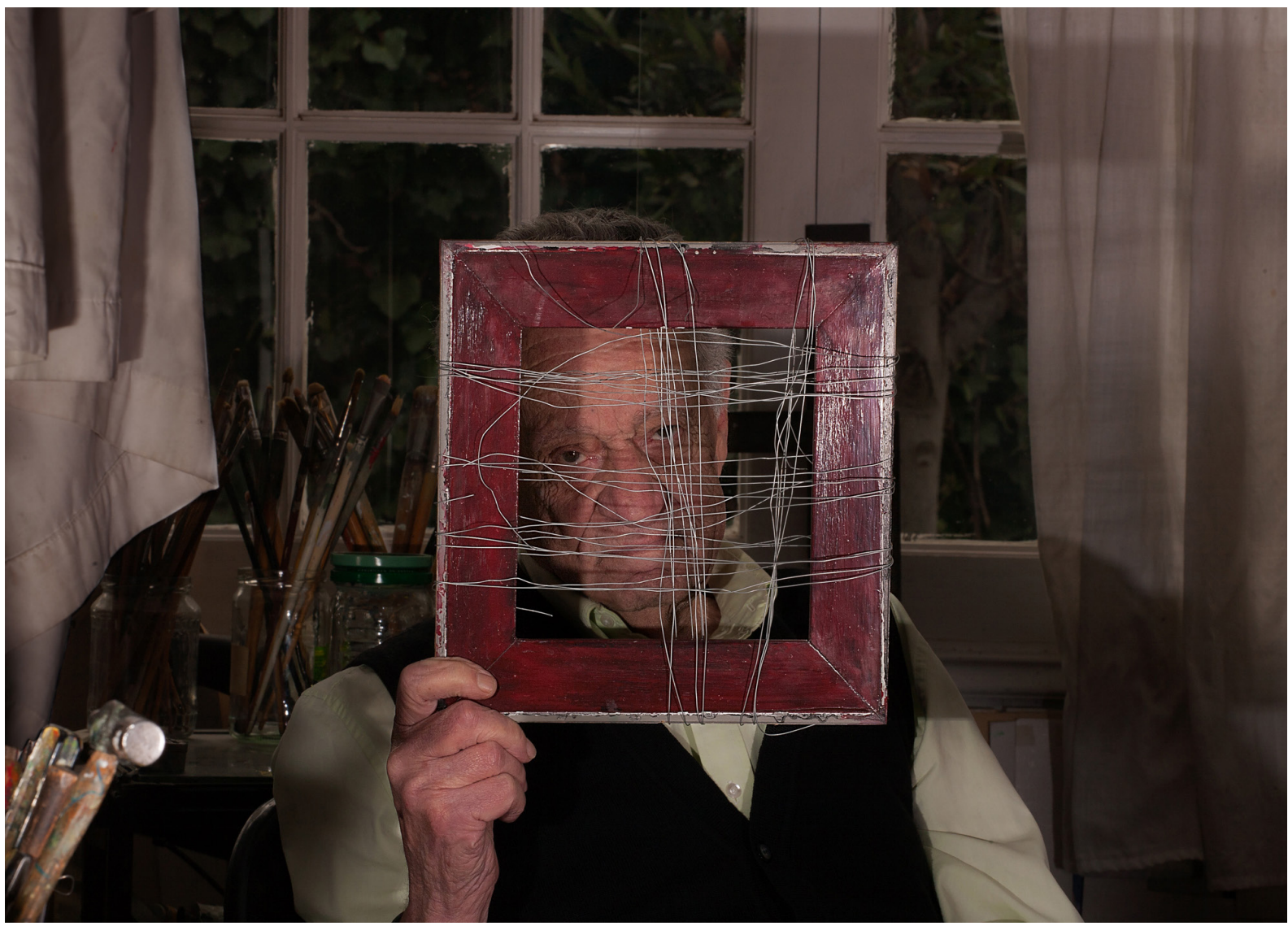

Figura 1. Kurt Herdan, sobreviviente del holocausto. Fuente: Fotografía de Samuel Shats, Proyecto En el Umbral del Olvido (2015).
Estados Unidos y países de Europa y Asia para finalizar en la ciudad japonesa de Osaka. La representación documental desplegada en fotografías blanco y negro se unía al ideario identitario nacional, quedando como parte de una mitología representacional impoluta e inalcanzable: Chile se congelaba en el tiempo de la memoria visual (Leiva, 2016).

\section{Una vuelta de tuerca: el post-testimonio}

La historia visual se fue ampliando con la irrupción del color. Gracias a los descubrimientos experimentales de Cros y Ducos de Hauron que buscaban la síntesis coloreada del siglo XIX se pasa a la fase de la "autocroma" del siglo XX (Frizot, 414). La fotografía color, tras superar las dificultades técnicas de su impresión en prensa y diarios así como su reproducción gracias a los avances del cine. Desde el tecnicolor hasta el cibacrom, el color se fue transformando en fidelidad gracias a sus tonos y la estabilidad de su permanencia. La estética color también fue ampliando su espectro, en la medida que no era invasiva del efecto aurático, que en particular en el registro familiar rodeaba la fotografía de una intimidad testimonial. El color vino a establecer una nueva retribución legítima en la medida que el color no solo era cualidad y verosimilitud sino también traspaso lumínico sobre los objetos y corporalidades. Sin duda que la fotografía de la prensa en revistas difundió esta operatividad y singularizó la experiencia con tendencia artística. El color ingresaba a la realidad documental y al ejercicio de lo que se ha denominado "fotografía de autor". Al respecto, tenemos un trabajo que nos hace reflexionar sobre los alcances de los testimonios tras tantos años. 


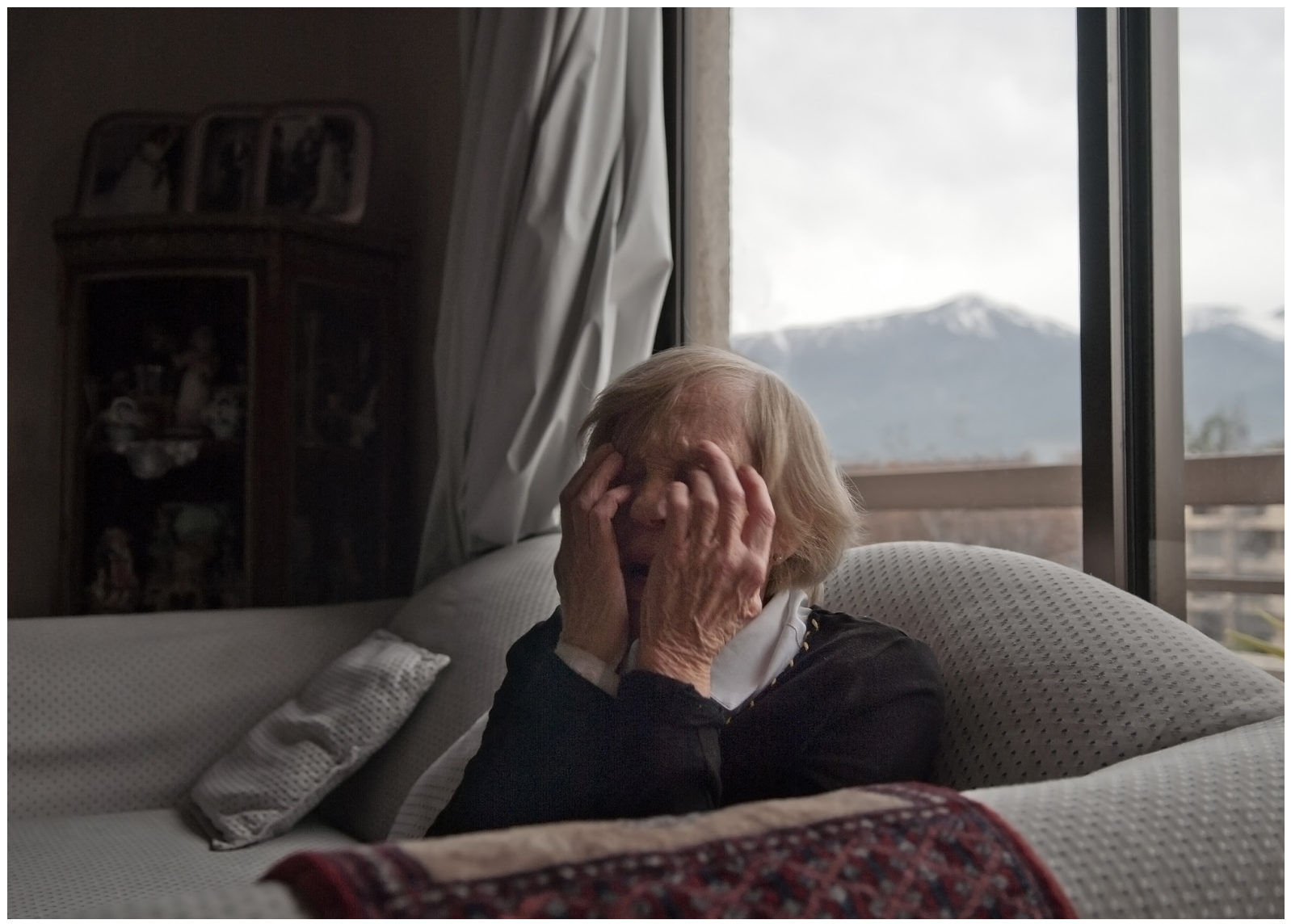

Me refiero al singular proyecto del fotógrafo Samuel Shats (Shats y Leiva, 2015) que organiza un zigzag emocional fraguado en torno a los sobrevivientes del holocausto en Chile. A diferencia de las fotos iniciales e históricas del Holocausto europeo con su carga expresiva de ojos y manos desamparadas, ahora el retrato se concentra en otros aspectos. Lo que antes hacía patente la vulnerabilidad en un cuerpo padecente, hoy dicha fragilidad alcanza otro estatus con la vejez y el olvido, la sobrevivencia enfrentada al lazo familiar, la ceguera, la inmovilidad, los temores a desaparecer, en definitiva a la indiferencia. El proyecto fotográfico “En el Umbral del Olvido” que fue exposición en el GAM y libro diseñado por Vicente Larrea, vigoriza el tratamiento de las metáforas como desplazamientos de las historias humanizadas. Es en definitiva, esta galería de personas, antiguos prisioneros de campos de concentración un significado desprendido de la memoria visual, donde la vida vuelve a ser desmenuzada y desplegada, como el fruto de la granada roja que muestra sus pequeños tesoros o arilos de ternura. Cabe adecuar las metonimias fotográficas con la noción de "correspondencia”, pues encajan en la lógica de la propia obra: hacer de la diversidad, imágenes que esparzan la memoria. Para esto sirven las metáforas visuales, para la recepción actual donde la construcción de un universo de intimidad poético y por lo mismo de experiencia propia que ahonde el peso de la conciencia histórica. El testimonio de los fotografiados traspasa la vivencia personal para constituirse en una experiencia del colectivo, incluso en este ensimismado Chile, país de miradas mediadas por los dispositivos tecnológicos.
Figura 2. Judith Klein, sobreviviente del holocausto. Fuente: Fotografía de Samuel Shats, Proyecto En el Umbral del Olvido (2015) 
Una metáfora como figura retórica asocia la base argumental; el tropo establece una semejanza entre dos unidades de significación que se relacionan e interactúan. Las metáforas son recursos estéticos que embellecen el lenguaje fotográfico realista. Dichas metáforas tensan por la variedad de formas una discursividad fotográfica lineal, pues al instalar sus dispositivos persuasivos no solo capturan a los sobrevivientes, sino también, las vulnerabilidades que rodean su vida actual, como adultos mayores sometidos al ejercicio tecnológico color de la fotografía.

El trabajo en imágenes de Samuel Shats construye un dispositivo estético contra el olvido. En Chile, una nación con una memoria frágil, se transforma este postestimonio en un tesoro que unifica el lazo social sobre los signos de barbarie. Pues delicadamente el conjunto de fotografías instalan la fuerza de lo simbólico y de la intimidad revuelta que va resarciendo y proyectando una nueva memoria visual desde un postestimonio.

Una conmemoración visual donde se dificulta ver los puntos de articulación por la gran avalancha de imágenes sin control, la compulsión a fotografiarlo "todo". No obstante, la mirada punzante de Shats levanta, sin aspavientos, una memoria insatisfecha con la historia. Ahora, de un modo evidente, estas estampas son más perceptibles en ciertas instancias, pero en todo momento continúan su acopio y "educación alfabética sentimental" de la población chilena. La fotografía chilena asume la acción de recordar como esfuerzo constante al reconocer la historia y sus evidentes contradicciones.

Por esto, el efecto calidoscopio que hemos configurado señala una heterocronía (Moxey, 2015, p. 84), donde se hacen visibles aspectos desenterrados de la historia, constituidos por múltiples temporalidades con la marca indeleble de una memoria del horror.

\section{Conclusiones}

Este es el mandato. Volver el imaginario desde el gesto de la oblación encarnada en el testimonio, en el cuerpo, en la mirada. En fin, en el crematorio, el sitio de memoria, el lugar de tortura, demostrando que no es el fin de todo sino el comienzo de una sensibilidad revisitada. Si bien la historia la hemos constituido por ciertos momentos de extravíos, historias traumáticas, obsesiones inútiles, quedan dichas huellas en la memoria visual. Constructo de conciencia tecnológica, ligado a principios éticos, a pesar de la amenaza constante y destructiva de huellas, la memoria visual continúa construyéndose. Los casos analizados constituyen ejercicio estéticos de marcas culturales dejadas por la sensibilidad artística que al mostrar y hablar de estos "enclaves de muertes" reinstala estas imágenes en el presente inmediato. En efecto, las relaciones estéticas de la creación y de la imagen se unen en la conciencia histórica, con el reconocimiento que las obras generan debates y reactualizan las matrices simbólicas del pensar contemporáneo. Sin duda, un pedazo del Chile profundo con la representación de un espacio cargado de afectos, sensibilidades y matrices identitarias, un nuevo "rostro de Chile" anclado en el presente y no el estereotipo de lo que fuimos.

La memoria visual es como una cueca melancólica que en las tardes de resolana calientan los cansados huesos de la comunidad. La magia fotográfica nos entrega los vestigios testimoniales y rinde con austeridad un sencillo homenaje a las invisibilidades de chilenos y chilenas que se esmeran por existir dignamente en un país de tantos olvidos, de tantas ausencias. 


\section{Bibliografía}

Agamben, G., (2011). ¿Qué es un dispositivo? Trad. R. J. Fuentes Rionda. Sociológica México, 26(73), 249264. Recuperado el 23.04.2017, de http://www. scielo.org.mx/scielo.php?script=sci_arttext\&pi$d=S 0187-01732011000200010 \& \operatorname{lng}=e s \& t \mid n g=e s$.

Bajtín, M. (1989). Teoría y estética de la novela. Trad. H. S. Kriúkova y V. Cazcarra. Madrid: Taurus.

Benjamin, W. (2005). Tesis sobre la historia y otros fragmentos. México: Contrahistorias.

Berger, J. y Mohr, J. (2013). Otra manera de contar. Barcelona: Gustavo Gili.

Bolaño, R. y Braithwaite, A. (2006). Bolaño por sí mismo: entrevistas escogidas. Santiago: Ediciones Universidad Diego Portales.

Collins, C., Hite, K. J., y Joignant, A. (2013). Las políticas de la memoria en Chile desde Pinochet a Bachelet. Santiago: Ediciones Universidad Diego Portales.

Déotte, J. L. (2013). La ciudad porosa, Walter Benjamin y la arquitectura. Santiago: Metales Pesados.

Febvre, L. (1947/1970). Combates por la historia. Barcelona: Ariel.

Fondevila Gascón, J. F. y Olmo Arriaga, J. L. (2013). El trabajo fin de grado en ciencias sociales y jurídicas: Guía metodológica. ( $2^{\mathrm{a}}$ ed.). Madrid: Ediciones Internacionales Universitarias.

Foucault, M. (2008). El gobierno de síy de los otros. Buenos Aires: FCE.

Foucault, M. (1977). Vigilary castigar. Nacimiento de la prisión. Buenos Aires: Siglo XXI.

Freud, S. (1976). Obras completas. Vol. 17. Madrid: Amorrortu. Frizot, M. (1994). Nouvelle Histoire de la Photographie. Paris: Borda.

García Fanlo, L. (2007). Sobre usos y aplicaciones del pensamiento de Michel Foucault en Ciencias Sociales. Discurso y Argentinidad, 2(2). Recuperado de: http:// sites.google.com/site/revistadiscursoyargentinidad/ Home/numero-2-primavera-de-2008.

Hilberg, R. (2005). La destrucción de los judíos europeos. Madrid: Akal.

Kristeva, J. (1989). Poderes de la perversión. ( $2^{\mathrm{a}}$ ed.). México: Siglo XXI.

Leiva, G. (2016). Álbum de Chile. Santiago: A Impresores. Leiva, G. (2016). Memórias e Holocaustos no Chile. Sao Paulo: Instituto de Estudios Avanzados, Universidad de Sao Paulo. Recuperado de http://www.iea.usp.br/midiateca/ video/videos-2016/memorias-e-holocaustos-no-chile

Lipovetsky, G. y Serroy, J. (2010). La cultura mundo. Respuesta a una sociedad desorientada. Barcelona: Anagrama.
Moxey, K. (2015). El tiempo de lo visual. Buenos Aires: Sans soleil.

Parque Cultural de Valparaíso (2016). Relatos de lucha e ideales. Valparaíso: GRS.

Ricoeur, P. (2000). La memoria, la historia y el olvido. Buenos Aires: FCE.

Shats, S. y Leiva, G. (2015). En el Umbral del Olvido. Santiago: Larrea Ediciones.

Vilanova, M., (2006). Rememoración y fuentes orales. En: V. Carnovale, F. Lorenz y R. Pittaluga (Comps.), Historia, memoria y fuentes orales. Buenos Aires: Cedinci. 